\title{
ANALISIS ANTENA BOWTIE PADA FREKUENSI 500-700 MHZ UNTUK TV DIGITAL DI INDONESIA
}

\section{ANALYSIS BOWTIE ANTENNA AT RANGE FREQUENCY 500 - 700 MHZ FOR DIGITAL TV INDONESIA}

\author{
Tengku Ahmad Riza 1, Yuyu Wahyu ${ }^{2}$, Reza Aldrian Ibrahim ${ }^{3}$ \\ ${ }^{1.3}$ Program Studi D3 Teknik Telekomunikasi, Fakultas Ilmu Terapan, Universitas Telkom \\ ${ }^{2}$ Pusat Penelitian Elektronika dan Telekomunikasi LIPI, Bandung \\ $1_{\text {tengkuriza@ telkomuniversity.ac.id, 2-yuyu@ppet.lipi.go.id, }}$-rezaldrian@gmail.com
}

\begin{abstract}
Abstrak
Tahun 2017 merupakan tonggak sejarah perubahan di Indonesia dari TV analog menjadi TV digital sesuai dengan Peraturan Menteri Kominfo No.05 Tahun 2012 yang mengadopsi Televisi Digital terestrial Digital Video Broadcasting-Terestrial second Generation (DVB-T2), sehingga diharapkan dengan perubahan menjadi TV Digital dapat meningkatkan kapasitas layanan melalui efisiensi spektrum frekuensi, dimana setelah migrasi ke TV Digital maka 1 kanal bisa ditempati sekitar 6-8 operator televisi. Pada Penelitian sebelumnya, telah dirancang dan direalisasikan sebuah antenna Bowtie, namun belum di implementasikan untuk siaran televisi digital di Indonesia.

Penelitian ini menggunakan metode desain, realisasi kemudian diimplentasikan dan dilakukan pengujian dan pengukuran sehingga menghasilkan suatu Antena Bowtie pada rentang frekuensi 500-700 $\mathrm{MHz}$ yang dipergunakan untuk antena penerima televisi digital di Indonesia tanpa menggunakan set top box dengan harga yang relatif murah.

Hasil Analisis dari antena Bowtie yang dipergunakan untuk televisi digital dengan rentang frekuensi 500-700 MHz didapatkan VSWR masing-masing $500 \mathrm{MHz}$ (VSWR=1,442) dan 600 $\mathrm{MHz}(\mathrm{VSWR}=1,448)$ serta $700 \mathrm{MHz}(\mathrm{VSWR}=1,442$ ) kemudian untuk penguatan 13,038 bisa menerima siaran televisi digital. Namun antena ini masih perlu untuk pengembangan ke depannya, karena antenna ini belum dikemas dengan baik dan sempurna.
\end{abstract}

Kata Kunci : TV Analog, TV Digital, DVB-T2, Bowtie, set top box

\begin{abstract}
2017 change history bollard in Indonesia from analogous TV become digital TV as according to Minister Kominfo No.05 2012 adopting terestrial Digital Television, Digital Video BroadcastingTerestrial second Generation (DVB-T2), so that expected with change become Digital TV can improve service capacities through frequency spectrum efficiency, where after migration to Digital TV, 1 canal can be taken possession about 6-8 television operator. Previous Research, have been designed and realized by a antenna Bowtie, but the implementation not yet for the digital telecast in Indonesia.

This research study about Bowtie Antenna Analysis at range frequency $500-700 \mathrm{MHz}$ for the receiving antenna digital television in Indonesia without using to set top box with the low price.

Result of Analysis from Bowtie antenna for the digital television at range frequency $500-700 \mathrm{MHz}$ got VSWR is at $500 \mathrm{MHz}$ (VSWR=1,442), $600 \mathrm{MHz}$ (VSWR=1,448), and $700 \mathrm{MHz}$ (VSWR=1,442), with gain 13,038 can accept digital telecast. But this antenna still need for the development, because this antenna not yet package better and perfect.
\end{abstract}

Keywords : Analog TV, Digital TV, DVB-T2, Bowtie, set up box 


\section{PENDAHULUAN}

Penyiaran televisi digital terrestrial adalah penyiaran yang menggunakan frekuensi radio VHF / UHF seperti halnya penyiaran analog, akan tetapi dengan format konten yang digital. Dalam penyiaran televisi analog, semakin jauh dari stasiun pemancar televisi signal akan makin melemah dan penerimaan gambar menjadi buruk dan berbayang. Lain halnya dengan penyiaran televisi digital yang terus menyampaikan gambar dan suara dengan jernih sampai pada titik dimana signal tidak dapat diterima lagi. Singkat kata, penyiaran TV digital hanya mengenal dua status: Terima (1) atau Tidak (0). Artinya, apabila perangkat penerima siaran digital dapat menangkap sinyal, maka program siaran akan diterima. Sebaliknya, jika sinyal tidak diterima maka gambar-suara tidak muncul ${ }^{[1]}$. Maka diperlukan suatu antena yang dapat menerima siaran televisi digital. Salah satu bentuk antena adalah antena Bowtie yang memiliki lebar bandwidth yang besar dan pola radiasi bidirectional cocok untuk antena penerima sinyal TV.

Berdasarkan latar belakang diatas, maka penulis ingin menganalisis penggunaan antena bowtie sebagai penerima antena televisi digital yang menggunakan material tembaga dan alumunium yang dapat bekerja pada rentang frekuensi 500-700 $\mathrm{MHz}$ dan juga dapat bekerja pada aplikasi televisi digital DVT-T2.

\section{DASAR TEORI}

\subsection{Antena}

Antena adalah sebuah perangkat yang digunakan untuk memancarkan dan/atau menerima gelombang elektromagnetik secara efisien. Antena akan mentransformasikan gelombang ruang bebas menjadi gelombang terbimbing [2].

\subsection{Antena Bowtie}

Antena Bowtie merupakan pengembangan dari antena bikonikal. Antena bikonikal memiliki pola radiasi yang unik namun cenderung besar dan tidak praktis [10] . Oleh karena itu antena bikonikal dikembangkan menjadi suatu antena yang memiliki dimensi lebih kecil dan lebih praktis yang disebut dengan antena Bowtie.

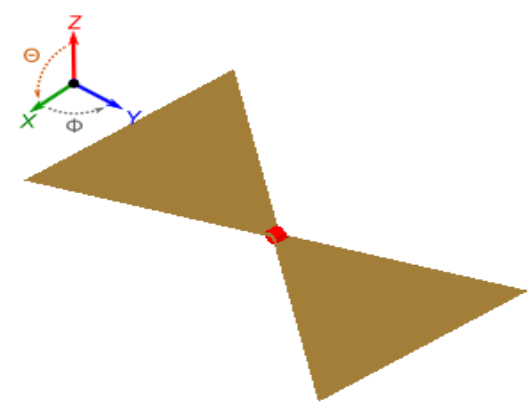

Gambar 1. Antena Bowtie [5]

Kelebihan utama dari antena Bowtie adalah impedansi yang lebar dan desain yang sederhana. Antena Bowtie dibuat dari dua buah lempeng segitiga yang terbuat dari logam yang diberi catuan di kedua sudutnya. Antena ini dipengaruhi oleh besar sudut segitiganya. Namun dalam pembuatan antena ini, jarak antara dua lempeng segitiga dan panjang lengan kedua segitiga harus dibatasi. Panjang lengan antena Bowtie biasanya tergantung pembuat. Biasanya panjang lengan antena Bowtie yang digunakan adalah sebesar $\mathrm{x} \lambda$ dengan $\lambda$ sebesar :

$$
\lambda=\frac{\mathrm{c}}{\mathrm{fr} \sqrt{\varepsilon_{\mathrm{r}}}}
$$




\subsection{Televisi Digital}

Televisi digital atau DTV adalah jenis televisi yang menggunakan modulasi digital dan sistem kompresi untuk menyiarkan sinyal gambar, suara, dan data ke pesawat televisi. Televisi digital merupakan alat yang digunakan untuk menangkap siaran TV digital, perkembangan dari sistem siaran analog ke digital yang mengubah informasi menjadi sinyal digital berbentuk bit data seperti komputer [wikipedia].

Penggunaan spektrum frekuensi untuk televisi analog dapat digunakan untuk penyiaran televisi digital. Perbandingan lebar pita frekuensi yang digunakan TV analog dan TV digital adalah 1 : 6. Artinya bila pada teknologi analog memerlukan pita selebar $8 \mathrm{MHz}$ untuk satu kanal transmisi, maka pada teknologi digital dengan lebar pita frekuensi yang sama dengan teknik multiplex, dapat memancarkan sebanyak 6 hingga 8 kanal transmisi sekaligus dengan program yang berbeda.

\section{Bandwidth Efficiency}

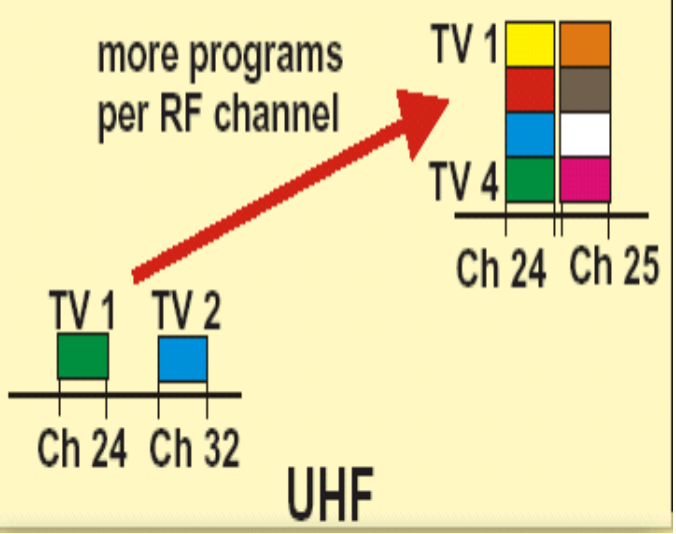

Gambar 2. Perbandingan Bandwidth tv analog dan tv digital [5]

\section{Penggunaan Frekuensi pada TV Digital}

* Pita spektrum frekuensi yang digunakan untuk televisi analog dapat digunakan untuk penyiaran televisi digital.

* Lebar pita frekuensi yang digunakan untuk analog dan digital berbanding $1: 6$.
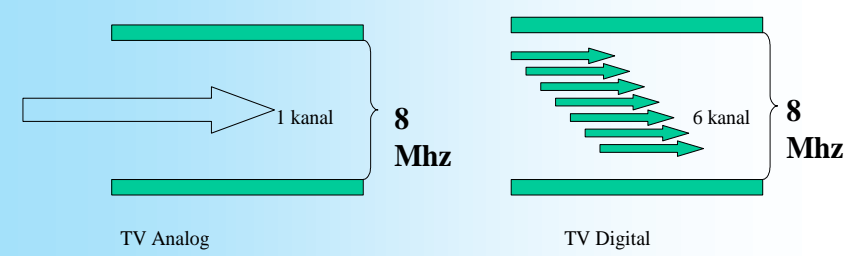

Teknologi digital efisien dalam pemanfaatan spektrum frekuensi. Satu penyelenggara televisi digital memanfaatkan spektrum dalam jumlah yang cukup besar. Artinya, tidak hanya 1 (satu) kanal pembawa melainkan lebih. Penyelenggara berfungsi sebagai operator penyelenggara jaringan, yang mentransmisikan secara teresterial program dari stasiun televisi lain menjadi satu paket layanan sebagaimana penyelenggaraan televisi kabel berlangganan yang ada saat ini.

Desain dan implementasi sistem siaran TV digital (terutama) ditujukan pada peningkatan kualitas gambar. TV digital memungkinkan pengiriman gambar dengan akurasi dan resolusi tinggi. Sistem TV digital mampu menghasilkan penerimaan gambar yang jernih, stabil, dan tanpa efek bayangan atau gambar ganda, walaupun pesawat penerima berada dalam keadaan bergerak dengan kecepatan tinggi. Sistem TV digital tidak mengenal gambar tidak jelas, gambar ganda (ghost), dan kualitas gambar buruk lainnya, karena pada teknik digital hanya dikenal "0" or "1". Gambar bagus atau tidak ada sama sekali.

Peraturan Menteri Komunikasi dan Informatika Republik Indonesia Nomor: 07/P/M.KOMINFO/3/2007 tentang Standar Penyiaran Digital Teresterial Untuk Televisi Tidak Bergerak di Indonesia menetapkan Standar Penyiaran Digital Teresterial Untuk Televisi tidak bergerak di Indonesia yaitu Digital Video Broadcasting-Terresterial (DVB-T) [5]. 


\section{PERANCANGAN ANTENA BOWTIE}

\subsection{Penentuan Spesifikasi Antena}

Antena Bowtie yang akan disimulasikan mempunyai spesifikasi sebagai berikut :

$>$ Frekuensi Kerja $: 500 \mathrm{MHz}-700 \mathrm{MHz}$

$>$ Impedansi Input $: 75 \Omega$

$>$ VSWR $: \leq 2$

$>$ Pola Radiasi

: Unidireksional

$>$ Polarisasi

: Linier

$>$ Gain $: \geq 12 \mathrm{dBi}$

Bahan yang digunakan dalam simulasi antena bowtie adalah plat kuningan dengan reflektor yang menggunakan plat aluminium yang sudah banyak terdapat di pasaran, dimana mempunyai spesifikasi sebagai berikut :

- panjang reflector

: $446 \mathrm{~mm}$

- lebar reflector

: $223 \mathrm{~mm}$

- sudut bowtie

: $60^{\circ}$

- panjang lengan

: $145 \mathrm{~mm}$

- jarak antara antena dan reflector

$: 150 \mathrm{~mm}$

\subsection{Pemilihan Bahan Antena}

Dalam pembuatan antena harus memperhatikan masalah bahan yang digunakan. Pemilihan dapat didasarkan pada kualitas bahan, nilai ekonomis bahan, dan ketersediaan bahan di pasaran. Pada realisasi antena ini digunakan bahan kuningan untuk antenanya dan aluminium untuk reflektornya karena kuningan dapat menghantarkan gelombang dengan baik, sedangkan untuk reflektornya menggunakan aluminium dengan mempertimbangkan nilai ekonomis bahan.

\subsection{Menentukan $\lambda$ (Panjang Gelombang) Antena Bowtie untuk Frekuensi $500 \mathrm{MHz}-700$} MHz

Sebelum melakukan perancangan lebih lanjut, pertama-tama ditentukan terlebih dahulu nilai $\lambda$ (panjang gelombang). Ini dapat dicari dari persamaan :

$>$ Untuk frekuensi $500 \mathrm{MHz}-700 \mathrm{MHz}$

$$
\begin{aligned}
& f_{c}=\frac{f_{L}+f_{H}}{2}=\frac{500 \times 10^{6}+700 \times 10^{6}}{2}=600 \times 10^{6}=600 \mathrm{MHz} \\
& \lambda=\frac{C}{f_{c}}=\frac{3 \times 10^{8}}{600 \times 10^{6}}=50 \mathrm{~cm}
\end{aligned}
$$

Untuk menghitung total panjang antena

$L=k \cdot \lambda=0,95 \cdot \lambda=0,95 \cdot 50 \mathrm{~cm}=47,5 \mathrm{~cm}$

Dimana :

$\lambda=$ Panjang gelombang di frekuensi tengah di udara

$L \quad=$ Arm length antena

$\mathrm{k}=$ Velocity factor untuk kuningan yang diambil sebesar 0,95

$\mathrm{fc} \quad=$ Frekuensi tengah $(\mathrm{Hz})$

C = Cepat rambat cahaya $(\mathrm{m} / \mathrm{s})$ 


\subsection{Dimensi Substrat}

Dimensi antena bowtie yang dibuat didapatkan dari panjang elemen dipole $L / 2$. Dari hasil perhitungan didapatkan $L=47.5 \mathrm{~cm}$, sehingga untuk satu elemen mempunyai panjang $23.75 \mathrm{~cm}$.

\section{PENGUKURAN DAN ANALISIS}

\subsection{Hasil Pengukuran VSWR}

Pada penelitian saat ini spesifikasi VSWR yang ditentukan adalah $\leq 2$. Pengukuran yang dilakukan dengan Network Analyzer dilakukan dengan rentang frekuensi $500 \mathrm{MHz}$ sampai dengan $700 \mathrm{MHz}$. Berikut adalah gambar cara pengukuran VSWR dan impedansi antena.

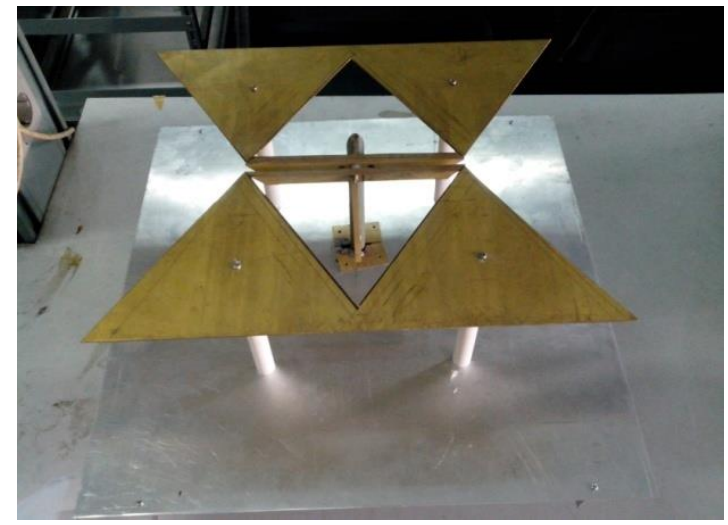

Gambar 3. Realisasi antena Bowtie

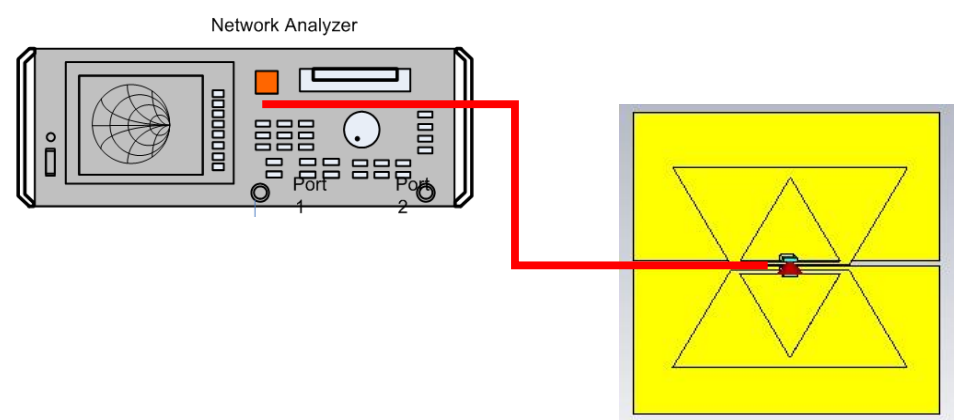

Gambar 4. Pengukuran VSWR, dan impedansi

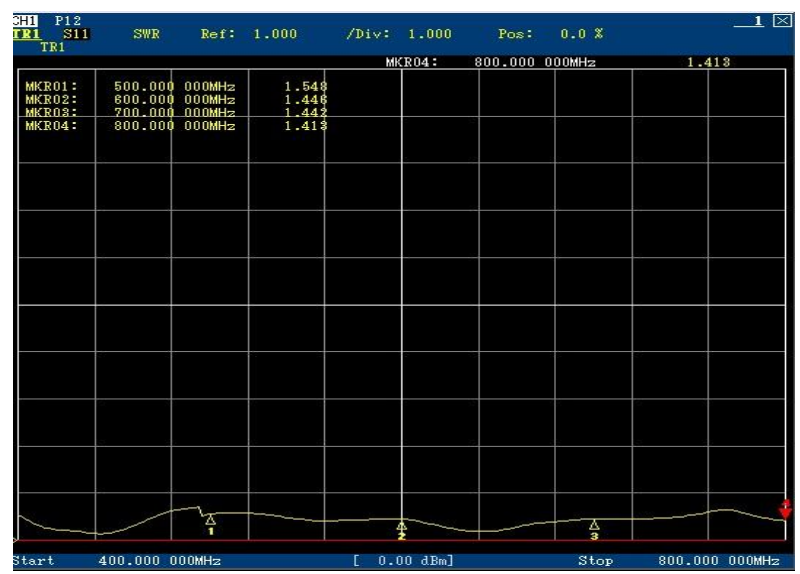

Gambar 5. grafik VSWR pengukuran antena 
Gambar 5 diatas adalah grafik VSWR pengukuran antena. Dari grafik VSWR tersebut terlihat bahwa antena bekerja pada frekuensi sesuai dengan perancangan awal yaitu $500 \mathrm{MHz}-700$ $\mathrm{MHz}$ dengan spesifikasi VSWR yang diharapkan $\leq 2$, meskipun terjadi pergeseran pada frekuensi tengah pada masing-masing bandwidth antena. Dari hasil pengukuran pada frekuensi $500 \mathrm{MHz}$, VSWR antena adalah 1,548 pada frekuensi $600 \mathrm{MHz}$, VSWR antena adalah 1,448 dan pada frekuensi $700 \mathrm{MHz}$, VSWR antena adalah 1,442.

\subsection{Hasil Pengukuran Impedansi Antena}

Prosedur pengukuran impedansi antena sama dengan pengukuran VSWR antena, alat ukur yang digunakan untuk mengukur impedansi antena menggunakan network analyzer. Pada pengukuran impedansi ini saluran transmisi dan port pada alat ukur memiliki spesifikasi tahanan 75 $\Omega$ sehingga agar terjadi transfer daya maksimum dari saluran transmisi ke antena jika impedansi antena mendekati $75 \Omega$. Berikut adalah hasil pengukuran impedansi antena.

Tabel 1. Impedansi Antena

\begin{tabular}{|c|c|}
\hline Frekuensi & Impedansi (Ohm) \\
\hline (MHz) & Pengukuran \\
\hline 500 & $40,194-\mathrm{j} 17,142$ \\
\hline 600 & $38,391+\mathrm{j} 12,081$ \\
\hline 700 & $53,982-\mathrm{j} 18,717$ \\
\hline
\end{tabular}

Dari hasil pengukuran tidak di dapat nilai impedansi antena sebesar $75 \Omega$, dengan kata lain antara impedansi antena dengan saluran transmisi tidak benar-benar matching sehingga tidak didapatkan nilai VSWR $=1$. Untuk itu dilakukan penyepadanan impedansi supaya antena yang direalisasikan dapat digunakan pada frekuensi kerja sesuai dengan spesifikasi.

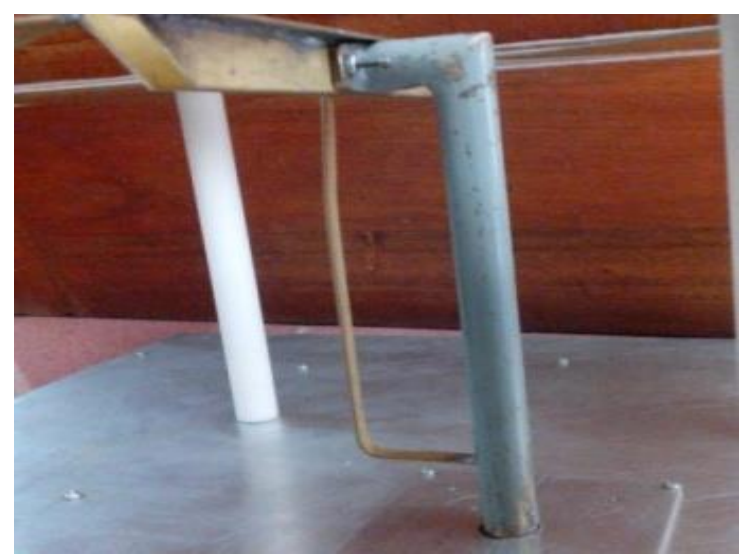

Gambar 6. penyepadanan impedansi antena

\subsection{Hasil Pengukuran Pola Radiasi Azimuth dan Pola Radiasi Elevasi}

Pola radiasi antena diukur pada daerah medan jauh antena, karena pada daerah tersebut gelombang elektromagnetik yang terpancar bersifat transversal penuh dan antena tidak dipengaruhi oleh benda di sekelilingnya. Adapun besarnya medan jauh untuk pengukuran ini agar nilai dihitung melalui persamaan: 


$$
R \geq \frac{2 L^{2}}{\lambda}
$$

dimana $\mathrm{L}$ adalah dimensi terbesar antena dan $\lambda$ adalah panjang gelombang. $\mathrm{L}$ pada antena Bowtie ini adalah diagonal dari groundplane yang panjangnya $\mathrm{L}=630,73 \mathrm{~mm}$, sedangkan $\lambda=\frac{C}{f_{c}}=\frac{3 \times 10^{8}}{600 \times 10^{6}}=50 \mathrm{~cm}$

$$
\text { medan jauh }=\frac{2 L^{2}}{\lambda}=\frac{2 \times 630,73^{2}}{500}=1591 \mathrm{~mm}
$$

Jadi $\mathrm{R} \geq 1591 \mathrm{~mm}$. Pada saat pengukuran jarak yang digunakan adalah $\mathrm{R}=1,6 \mathrm{~m}$

Polaradiasi antena merupakan representasi dari perbandingan level daya yang keluar dari antena dalam berbagai arah. Polaradiasi antena diukur pada daerah medan jauh antena, karena pada daerah tersebut gelombang elektromagnetik yang terpancar bersifat transversal penuh. Polaradiasi diukur dengan meletakkan antena secara vertikal maupun horisontal. Prosedur yang dilakukan pada proses pengukuran polaradiasi antena adalah sebagai berikut:

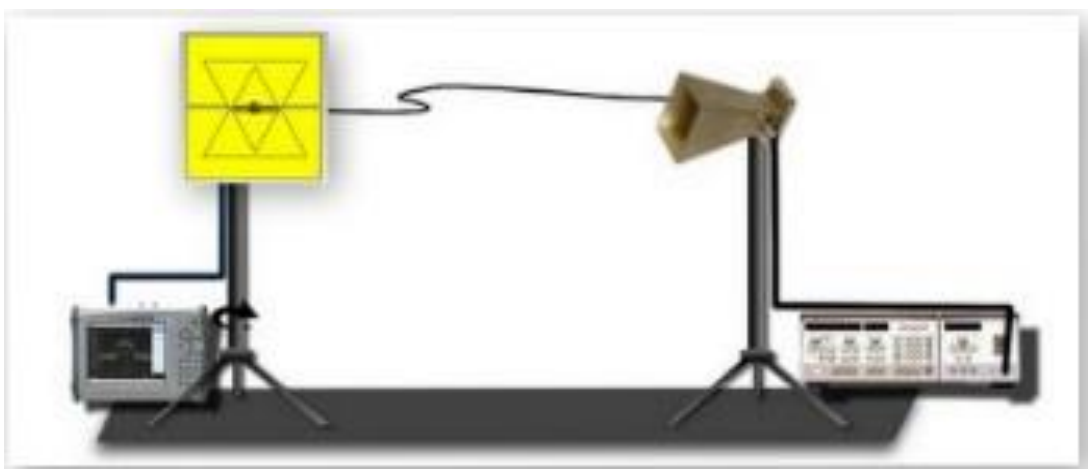

Gambar 7. Pengukuran Polaradiasi Antena

Frekuensi kerja yang digunakan adalah frekuensi UHF (500 MHz - $700 \mathrm{MHz})$.

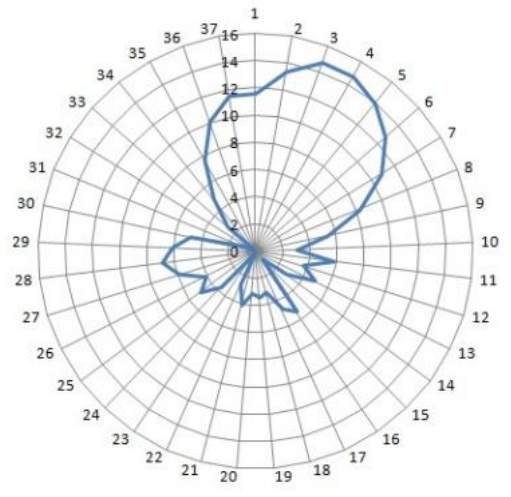

(a)

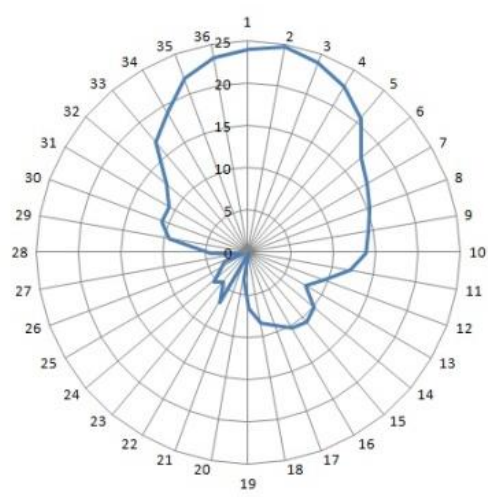

(b)

Gambar 8. Pola radiasi azimuth dan pola radiasi elevasi.

(a) Pola Radiasi Azimuth. (b) Pola Radiasi Elevasi

Gambar 8. menunjukan bahwa hasil pengukuran untuk pola radiasi azimuth maupun elevasi yaitu pola radiasi yang terpancar ke satu arah, jadi spesifikasi awal pembuatan antena terpenuhi, yaitu unidireksional. 


\subsection{Hasil Pengukuran Gain Antena}

Tabel 2. Pengukuran Gain Antena

\begin{tabular}{|c|c|c|}
\hline No & Daya Terima Max AUT $(\mathbf{d B m})$ & Daya Terima Max Referensi $(\mathbf{d B m})$ \\
\hline 1 & -33.11 & -51.11 \\
\hline 2 & -33.45 & -50.75 \\
\hline 3 & -32.12 & -52.33 \\
\hline 4 & -33.78 & -51.28 \\
\hline 5 & -31.52 & -51.21 \\
\hline 6 & -32.47 & -52.17 \\
\hline 7 & -32.98 & -53.13 \\
\hline 8 & -33.18 & -53.01 \\
\hline 9 & -32.75 & -50.64 \\
\hline 10 & -31.89 & -51.54 \\
\hline Average & $\mathbf{- 3 2 . 7 2 5}$ & $\mathbf{- 5 1 . 7 1 7}$ \\
\hline Gain (dBi) & & $\mathbf{1 2 . 0 8 8}$ \\
\hline
\end{tabular}

Tabel di atas merupakan hasil pengukuran gain antena dengan 10 kali percobaan, hasil dari pengukuran tersebut di dapatkan rata-rata gain antena 12,088 $\mathrm{dBi}$ dan sudah memenuhi dari perancangan awal antena yaitu $\geq 12 \mathrm{dBi}$.

\section{KESIMPULAN}

1. Pada pengukuran VSWR, nilai VSWR yang didapat pada frekuensi $500 \mathrm{MHz}$ adalah 1.548 , pada frekuensi $600 \mathrm{MHz}$ nilai VSWR adalah 1.448, dan pada frekuensi $700 \mathrm{MHz}$ nilai VSWR adalah 1.442. Dengan hasil ini tujuan awal dari pembuatan tugas akhir ini tercapai karena nilai VSWR $\leq 2$.

2. Pola radiasi azimuth maupun elevasi yaitu pola radiasi yang terpancar ke satu arah, jadi spesifikasi awal pembuatan antena terpenuhi, yaitu unidireksional.

3. Gain antena rata-rata adalah $12,088 \mathrm{dBi}$ dan sudah memenuhi dari perancangan awal antena yaitu $\geq 12 \mathrm{dBi}$.

4. Antena Bowtie dapat digunakan sebagai antena penerima TV digital pada frekuensi $500-700$ $\mathrm{MHz}$ di Indonesia.

\section{Daftar Pustaka:}

[1] Alaydrus, Mudrik. 2011. Antena Prinsip \& Aplikasi. Yogyakarta:Graha Ilmu.

[2] Aswoyo, Budi. 2007. Antena \& Propagasi . Surabaya:Institut Teknologi Sepuluh Nopember.

[3] Balanis, Constantine A. 1997. Antenna Theory : Analysis And Design. New York:John Wiley \& Sons, Inc.

[4] Collin, Robert E. 2001. Foundations for Microwave Engineering. New York: John Wiley \& Sons, Inc. 
[5] Ibrahim, Reza A. 2013. Desain dan Realisasi Antena Bowtie Pada Frekuensi $500 \mathrm{MHz}-700$ MHz untuk Aplikasi TV Digital (DVB-T dan DVB-T2) di Indonesia. Bandung. Institut Teknologi Telkom.

[6] Jensen, Steve. 2010. Microstrip Patch Antenna. Northern Arizona University.

[7] Kraus, John D. 2001. Antennas. New York:The McGraw-HillCompanies.

[8] Tuwono, Tito. 2008. Yagi Antenna Design For Wireless LAN 2,4 GHz. Jogjakarta:Universitas Islam Indonesia.

[9] Volakis, John L. 2007. Antenna Engineering Handbook. The McGraw-Hill Companies

[10] Wijaya, I Made Maha. 2009. Perancangan dan Realisasi Antena Sierpinski Triangle Bowtie pada Frekuensi 2300-2400 MHz. Bandung:Institut Teknologi Telkom

[11] __ Impedansi 50 atau $75 \mathrm{Ohm}$ http://www.2wijaya.com/Impedansi_50_75ohm.htm diunduh pada 21 Juni 2013.

[12] __ Televisi Digital di Indonesia http://id.wikipedia.org/wiki/Televisi digital di Indonesia diunduh pada 24 Juni 2013. 